\title{
Práticas extensionistas no contexto da Proex/Unitins: um caminho para superação das desigualdades sociais em tempos de mudanças no sistema educacional
}

\author{
Kyldes Batista Vicente1 \\ Soely Kunz Cericatto2 \\ Mylena Costa Jacundá3
}

\begin{abstract}
RESUMO
Neste artigo analisa-se algumas práticas extensionistas desenvolvidas no âmbito da Pró-Reitoria de Extensão, Cultura e Assuntos Comunitários da Universidade Estadual do Tocantins (Proex/Unitins), durante os meses de janeiro de 2019 a março de 2020. O objetivo é refletir acerca das ações de extensão desenvolvidas em tempos de mudanças no sistema educacional. Optou-se pelo método descritivo, de abordagem qualitativa, cuja técnica foi a análise de projetos e de relatórios de projetos já finalizados ou em andamento. Para a fundamentação utilizou-se da legislação vigente sobre Extensão Universitária e das contribuições de autores que tratam dessa temática. Com os resultados alcançados, conclui-se que as práticas extensionistas desenvolvidas possibilitaram experiências significativas, tanto na vida pessoal quanto profissional dos envolvidos, oportunizando o desenvolvimento de atividades educativas e de cunho social em diversas áreas do conhecimento, constituindo-se em um espaço de promoção do exercício da cidadania, construção de aprendizagem e diálogos com a comunidade externa.
\end{abstract}

\footnotetext{
${ }^{1}$ Doutora em Comunicação e Cultura Contemporâneas pela Universidade Federal da Bahia (UFBA). Professora da Universidade Estadual do Tocantins (Unitins), Palmas-Tocantins-Brasil. Orcid http://orcid.org/0000-0002-84732828. E-mail: kyldes.bv@unitins.br.

${ }^{2}$ Mestre em Educação pela Universidade Federal do Tocantins (UFT), Palmas-TO. Professora da Universidade Estadual do Tocantins (Unitins), Palmas-Tocantins-Brasil. Orcid: https://orcid.org/0000-0002-3272-9619. E-mail: soely.kc@ unitins.br.

${ }^{3}$ Graduada em Direito pela Universidade Federal do Tocantins(UFT), Palmas-TO. Coordenadora de Extensão da Universidade Estadual do Tocantins (Unitins). Orcid: https://orcid.org/0000-0003-0583-7275. E-mail: mylena.cj@unitins.br.
} 
PALAVRAS-CHAVE: Práticas Extensionistas. Contribuições. Formação do aluno. Superação das desigualdades sociais.

Extension practices in the context of Proex / Unitins: a way to overcome social inequalities in times of changes in the educational system

\begin{abstract}
This article analyzes some extension practices developed within the scope of the Dean of Extension, Culture and Community Affairs of the State University of Tocantins (Proex / Unitins), from January 2019 to March 2020. The aim is to reflect on extension actions developed in times of changes in the educational system. It was opted for the descriptive method, with a qualitative approach, whose technique was the analysis of projects and reports of projects already completed or in progress. For the reasons we used the current legislation on University Extension and the contributions of authors who deal with this theme. With the results achieved, it is concluded that the extension practices developed enabled significant experiences, both in the personal and professional lives of those involved, enabling the development of educational and social activities in different areas of knowledge, constituting a space for promotion the exercise of citizenship, construction of learning and dialogues with the external community.
\end{abstract}

KEYWORDS: Extensionist practices. Contributions. Student training. Overcoming social inequalities.

Prácticas extensionistas en el contexto de Proex/Unitins: un camino para superar las desigualdades sociales en tiempos de cambio en el sistema educativo

\title{
RESUMEN
}

En este artículo se analizan algunas prácticas extensionistas desarrolladas en el marco de la Pro-Rectoría de Extensión, Cultura y Asuntos Comunitarios de la Universidad Estatal de Tocantins (Proex/Unitins), durante los meses de enero de 2019 a marzo de 2020. El objetivo es reflexionar sobre las acciones de extensión desarrolladas en tiempos de cambios en el sistema educativo. Se eligió el método descriptivo, de enfoque cualitativo, cuya técnica era el análisis de proyectos e informes de proyectos ya finalizados o en curso. Para fundamentar esto, utilizamos la legislación actual sobre la Extensión Universitaria y las contribuciones de los autores 
que se ocupan de este tema. Los resultados obtenidos muestran que las prácticas extensionistas desarrolladas han permitido experiencias significativas, tanto en la vida personal como profesional de los involucrados, brindando oportunidades para el desarrollo de actividades educativas y sociales en diversas áreas del conocimiento, y proporcionando un espacio para promover el ejercicio de la ciudadanía, construyendo el aprendizaje y el diálogo con la comunidad externa.

PALABRAS CLAVE: Prácticas Extensionistas. Contribuciones. Formación del estudiante. Superar las desigualdades sociales.

\section{Introdução}

O início do século XXI é marcado por várias transformações sociais, políticas, econômicas e globais. Entre elas estão as mudanças no sistema educacional, relacionadas ao desenvolvimento acelerado das tecnologias da comunicação e informação, que impõem uma série de novos e constantes desafios a serem enfrentados pela sociedade contemporânea.

Adequações e novas regulamentações foram necessárias para que as Instituições de Educação Superior pudessem acompanhar essa evolução e continuar sendo responsáveis pela produção, preservação e difusão dos conhecimentos culturais, científicos e tecnológicos, tornando esse conhecimento acessível a todos.

Para que a IES esteja preparada, e preparar cada vez mais os alunos para enfrentar esse mundo competitivo, que além do conhecimento conteudístico, é necessário prepará-lo para ser um profissional de destaque, de talento em suas ações. Esse aluno/egresso terá que saber lidar com os mais diferentes problemas na vida real, profissional e situações sociais, construindo uma sociedade mais justa e igualitária.

Pelo Art. 207. da Constituição Federal de 1988, "As universidades gozam de autonomia didático-científica, administrativa e de gestão financeira e patrimonial, e obedecerão ao princípio de indissociabilidade 
entre ensino, pesquisa e extensão". Diante desse dispositivo, entende-se a Extensão Universitária como um processo educativo, cultural e científico que articula o ensino e a pesquisa de forma indissociável. Em tempos de mudanças no sistema educacional, a extensão desempenha um papel fundamental no contexto das universidades e comunidade externa.

Considerando essa realidade e pensando que a "educação é um direito de todos" (CF/1988) e que universidade é o local que buscamos conquistar nossos sonhos, como profissionais, contribuindo para a superação das desigualdades sociais, busca-se, por meio deste texto, apresentar/descrever algumas das contribuições referentes às práticas extensionistas desenvolvidas no contexto da Pró-Reitoria de Extensão, Cultura e Assuntos Comunitários da Universidade Estadual do Tocantins (Proex/Unitins), no período de janeiro de 2019 a março de 2020, cujo objetivo é refletir e tornar essas práticas transparentes.

Ressalta-se que as referidas ações foram desenvolvidas em tempos de mudanças no sistema educacional, evidenciando suas contribuições e benefícios para a formação do aluno e superação das desigualdades sociais na contemporaneidade.

As motivações que nos levaram a optar por esse estudo têm ligação com o trabalho que ora é desenvolvido pelas autoras na Proex/Unitins, e também porque as pesquisas, nessa área, são necessárias, pois contribuem para a indicação de respostas para a superação das desigualdades sociais.

Para a fundamentação, utilizou-se da legislação vigente e das Diretrizes e Política Nacional de Extensão, e da Política de Extensão da Unitins, e das contribuições de autores que tratam dessa temática. Já para o desenvolvimento optou-se pelo método estudo descritivo, de abordagem qualitativa. A técnica utilizada para a concretização dos resultados foi a análise dos projetos e análise dos relatórios finais dos projetos já executados nos diversos Câmpus da Unitins.

Para a concretização dessa pesquisa, foi necessário estruturar o presente artigo em duas seções: na primeira, uma abordagem sobre a 
Extensão Universitária no Brasil e na segunda, é apresentada a descrição de algumas das práticas/ações extensionistas desenvolvidas no contexto da Proex/Unitins, de janeiro de 2019 a março de 2020, evidenciando-se as contribuições e benefícios para a formação do aluno e superação das desigualdades sociais na contemporaneidade.

\section{Trajetória Normativa e Conceitual da Extensão Universitária no Brasil}

Para entender a trajetória normativa, apresentamos uma breve retrospectiva (recorte) referente ao Marco Legal e Conceitual da Extensão Universitária no Brasil, a partir de 1987, partindo do primeiro encontro de Pró-reitores de Extensão das Universidades Públicas Brasileiras (Forproex), realizado em Brasília, nos dias 4 e 5 de novembro de 1987. Esse encontro representou um grande avanço para a Extensão que, além de proporcionar várias reflexões sobre a institucionalização e sobre o financiamento da extensão universitária, nele foi definido o novo conceito de extensão que passou a vigorar nos seguintes termos:

A extensão universitária é o processo educativo, cultural e científico que articula o ensino e a pesquisa de forma indissociável e viabiliza a relação transformadora entre Universidade e Sociedade.

A extensão é uma via de mão-dupla, com trânsito assegurado à comunidade acadêmica, que encontrará, na sociedade, a oportunidade de elaboração da práxis de um conhecimento acadêmico. No retorno à Universidade, docentes e discentes trarão um aprendizado que, submetido à reflexão teórica, será acrescido àquele conhecimento. Esse fluxo, que estabelece a troca de saberes sistematizados, acadêmico e popular, terá como conseqüências a produção do conhecimento resultante do confronto com a realidade brasileira e regional, a democratização do conhecimento acadêmico e a participação efetiva da comunidade na atuação da Universidade. (FORPROEX, 1987, p. 11). 
Durante os encontros do Forproex ${ }^{4}$ é que são verificadas as necessidades de ampliação dos programas de desenvolvimento de políticas de financiamento, de aperfeiçoamento de políticas e instrumentos de fomento e apoio à Extensão Universitária, pois entende-se que estas são indissociáveis e são uma forma de integração da extensão no âmbito das IES públicas. O Forproex é uma alternativa de fortalecimento das Universidades Públicas Brasileiras para a superação das desigualdades sociais.

Em 1988, a Constituição Federal deixa evidente no Art. 207 que "As universidades gozam de autonomia didático-científica, administrativa e de gestão financeira e patrimonial, e obedecerão ao princípio de indissociabilidade entre ensino, pesquisa e extensão”. Já o Art. 213. [...] parágrafo $2^{\circ}$ diz que "As atividades universitárias de pesquisa e extensão poderão receber apoio financeiro do Poder Público”, reafirmando o conceito de Extensão definidos no primeiro Forproex de 1987, já que, além de constitucionalizar, atribui a ela o caráter indissociável do Ensino e da Pesquisa, dando à Extensão a possibilidade do recebimento de apoio financeiro do Poder Público.

Em seguida, a Lei de Diretrizes e Bases da Educação Nacional ${ }^{5}$ (LDB-Lei $\mathrm{n}^{\circ}$ 9.394/1996), de 20 de dezembro de 1996, abre caminhos para a IES cumprir o seu papel social, proporcionando à Extensão a oportunidade de criar, estabelecer planos, programas e projetos de pesquisa científica, produção artística e atividades de extensão. A lei evidencia que as atividades universitárias de pesquisa e extensão poderão receber apoio financeiro do Poder Público, inclusive mediante bolsas de estudo.

Com a LDB (Lei nº 9.394/1996), a Extensão Universitária assume a responsabilidade teórica e prática na organização de suas ações, pois o intuito é a divulgação do conhecimento, a formação acadêmica e

\footnotetext{
4 Vide sítio https://www.ufmg.br/proex/renex/index.php/documentos/cartas-e-memoria - Cartas e Memória - Encontros Nacionais do FORPROEX. Acesso em: 12 de setembro de 2020. (RENEXRede Nacional de Extensão).

${ }^{5}$ Vide sítio http://www.planalto.gov.br/ccivil_03/Leis/L9394.htm. Acesso em: 6 de setembro de 2020.
} 
profissional do aluno e a redução das desigualdades sociais tanto local, como regional e/ou nacional.

Em seguida, o Plano Nacional de Educação (PNE, 2001-2010) aprovado pela Lei n. ${ }^{\circ} 10.172$, de 9 de janeiro de 2001, considerado o primeiro plano instituído por lei, e elaborado para a construção de políticas e programas com o intuito de melhorar da educação (BRASIL, 2014), determinou a Meta 23, que preconiza a implantação do Programa de Desenvolvimento da Extensão Universitária em todas as Instituições Federais de Ensino Superior no quadriênio 2001-2004 e assegura que, no mínimo, 10\% do total de créditos exigidos para a graduação no ensino superior no País deverá ser reservado para a atuação dos alunos em ações extensionistas.

Em 2012, a Política Nacional de Extensão Universitária (FORPROEX, 2012, p. 28) estabeleceu que:

Extensão Universitária sob o princípio constitucional da indissociabilidade entre ensino, pesquisa e extensão, é um processo interdisciplinar, educativo, cultural, científico e político que promove a interação transformadora entre Universidade e outros setores da sociedade.

Nesse sentido, a Extensão Universitária visa à transformação, tanto na universidade, como nos diferentes setores da sociedade nos quais ela tem oportunidade de interagir.

Segundo Nogueira (2000), a formulação e a implementação das ações de Extensão Universitária devem seguir as diretrizes adotadas pela Política Nacional de Extensão, pactuadas no Fórum de Pró-Reitores de Extensão das Instituições Públicas de Educação Superior Brasileiras (FORPROEX, 2012). Entre as diretrizes a serem seguidas ficou definido: Interação Dialógica; Interdisciplinaridade e Interprofissionalidade; Indissociabilidade Ensino-Pesquisa-Extensão; Impacto na Formação do Estudante; e Impacto e Transformação Social.

A Política Nacional de Extensão (2012) também preconiza a participação de estudantes nas ações de Extensão e estas ações devem estar 
sustentadas em iniciativas que viabilizem a flexibilização curricular e a integralização dos créditos logrados nas ações de Extensão Universitária. (FORPROEX, 2012, p. 19). Para Boaventura de Sousa Santos (2004, p. 53),

[...] a área de extensão vai ter no futuro próximo um significado muito especial. No momento em que o capitalismo global pretende funcionalizar a Universidade e, de facto, transformá-la numa vasta agência de extensão ao seu serviço, a reforma da Universidade deve conferir uma nova centralidade às atividades de extensão (com implicações no curriculum e nas carreiras dos docentes) e concebê-las de modo alternativo ao capitalismo global, atribuindo às Universidades uma participação activa na construção da coesão social, no aprofundamento da democracia, na luta contra a exclusão social e a degradação ambiental, na defesa da diversidade cultural.

É a extensão que alcança o sentido da universidade na sua totalidade, uma vez que consegue articular as atividades universitárias como um todo e construindo a coesão social.

No Plano Nacional de Educação (PNE, 2014-2024), aprovado pela Lei n. ${ }^{\circ}$ 13.005, de 25 de junho de 2014, ficou estabelecido um número reduzido de metas, porém, determinou algumas metas e estratégias urgentes tais como a Meta 12 (elevar a taxa bruta de matrícula na educação superior) e a Estragégia 12.7 (que assegura, no mínimo, dez por cento do total de créditos curriculares exigidos para a graduação em programas e projetos de extensão universitária, orientando sua ação, prioritariamente, para áreas de grande pertinência social).

No Plano Nacional de Educação (PNE - 2014 a 2024) foram apresentadas algumas inovações para a realidade educacional das universidades brasileiras, deixando o desafio para que as IES revejam suas concepções e práticas extensionistas e curriculares.

Apesar das inúmeras Políticas de Educação Superior ligadas à Extensão Universitária, somente em 2018, é que essa Política realmente foi regulamentada pela RESOLUÇÃO $\mathbf{N}^{\mathbf{0}} \mathbf{7}$, de 18 de dezembro de 2018. Essa Resolução estabelece as Diretrizes para a 
Extensão na Educação Superior Brasileira e regimenta o disposto na Meta 12.7 da Lei $\mathrm{n}^{\circ}$ 13.005/2014, que aprova o Plano Nacional de Educação - PNE 2014-2024 e dá outras providências.

As Políticas de Educação Superior vinculadas à Extensão tiveram um avanço significativo, sendo que essa Resolução se caracteriza como um marco regulatório para a Extensão, pois além de instituir as Diretrizes para a Extensão na Educação Superior Brasileira, reforça o compromisso social das Instituições de Educação Superior.

O próximo passo neste texto é entender as Política de Extensão da Universidade Estadual do Tocantins (Unitins), uma vez que este artigo trata das práticas extensionistas em tempos de mudanças educacionais na Proex/Unitins.

\section{Política de Extensão da Universidade Estadual do Tocantins (Unitins)}

A Política de Extensão da Unitins pauta-se no princípio de que o conhecimento é um processo social e coletivo indissociável do ensino, pesquisa e extensão, que visa proporcionar à sociedade aportes de conhecimentos destinados a superar os entraves de seu desenvolvimento, recebendo de igual maneira as contribuições de suas vivências e experiências. (POLÍTICA DE EXTENSÃO UNIVERSITÁRIA, 2017,p.6 e PDI 2018-2022, p.42)

Em relação à Política de Extensão, é importante destacar que a Universidade Estadual do Tocantins (Unitins) cupre o seu papel social como Instituição de Educação Superior por meio da execução de práticas/ações extensionistas que procuram suprir as demandas de desigualdades sociais existentes na comunidade externa. Para isso, além de seguir as Políticas e Diretrizes Nacionais, segue suas próprias regulamentações:

RESOLUÇÃO/CONSEPE/N. 005/2017 - Esta Resolução aprova a Política de Extensão da Unitins e aprova a INSTRUÇÃO NORMATIVA/CONSEPE/N. 001/2017 que dispõe sobre os procedimentos 
operacionais para a institucionalização de ações de extensão na Unitins, caracterizando a extensão como um processo interdisciplinar, educativo, cultural, social, científico e político representado por um conjunto de ações visando à articulação do ensino e da pesquisa de forma indissociável, viabilizando a relação transformadora entre a Universidade e outros setores da sociedade. É pertinente destacar que tais diretrizes estão vinculadas ao Plano de Desenvolvimento Institucional (PDI, 2018-2022, p.43) da Unitins.

Pela regulamentação, as atividades de extensão devem compor, no mínimo, 10\% (dez por cento) da carga horária total dos cursos de graduação em programas e projetos de extensão universitária, conforme determina a estratégia 12.7 do Plano Nacional de Educação (PNE 2014-2024) e Resolução no 7, de 18 de dezembro de 2018.

Segundo o PDI (2018-2022, p 44), a Extensão Universitária é fundamental para a formação do profissional, pois, em seu espaço dinâmico de aprendizagem, enseja a interdisciplinaridade, a interprofissionalidade, a dialogicidade e viabiliza uma relação transformadora entre a Universidade e a sociedade.

É importante destacar que, em relação à tramitação das propostas, registros e aprovação das ações de extensão, estas deverão ser apresentadas por docentes ou técnicos administrativos de nível suprior, envolvendo alunos e comunidade externa seguindo as normativas.

Além disso, as ações de extensão da Unitins deverão observar os princípios institucionais da extensão universitária e promover o desenvolvimento local e/ou regional, sendo que as propostas de projetos de extensão deverão seguir, obrigatoriamente, o Formulário Único de Proposta de Extensão - FUPE.

Segundo essa Instrução Normativa Art. 47, o financiamento das ações de extensão da Unitins serão assegurados por meio de recursos próprios, oriundos de programas da Unitins e/ou consignados no Tesouro Estadual, cabendo à Pró-Reitoria de Extensão, Cultura e Assuntos 
Comunitários a abertura de edital pra seleção de ações de extensão que demandarem recursos financeiros da Unitins.

Essa Instrução Normativa também determina que as ações de extensão serão institucionalmente avaliadas por meio de critérios e análise dos resultados, atendendo às diretrizes de Avaliação Nacional de Extensão Universitária.

Nessa mesma direção, e atendendo às recomendações dos Planos Nacionais de Educação, e da RESOLUÇÃO $\mathrm{N}^{\circ} 7$, de 18 de dezembro de 2018, publicada no DOU, no dia 18 de dezembro de 2018, a Unitins aprovou INSTRUÇÃO NORMATIVA/UNITINS/N. 005/2019/GABREITOR, de 10 de dezembro de 2019, publicada no Diário Oficial do Tocantins, no dia 13 de dezembro de 2019. Essa Instrução Normativa regulamenta as ações de extensão como componente curricular obrigatório nos projetos pedagógicos dos cursos de graduação da Universidade Estadual do Tocantins, conforme preconiza a a legislação.

De uma forma geral, percebe-se que o Plano Nacional de Educação (PNE) é um documento que ampara os documentos institucionais como PPI, PDI, Regimentos, Regulamentos, Portarias, associados às diretrizes e legislações específicas dos cursos.

Nesse sentido, a Unitins procura sistematizar suas diretrizes e desenvolver suas ações de extensão de acordo com: a Constituição da República Federativa do Brasil (1988, Art.207) e com a Política Nacional de Extensão Universitária (FORPROEX /2012), com o Plano Nacional de Educação (Lei No 13.0052014 - Meta 12; Estratégia 12.7), com a RESOLUÇÃO/CONSEPE/N. 005/2017 e INSTRUÇÃO NORMATIVA/ CONSEPE/N. 001/2017, e com seu estatuto.

Nessa seção, apresentamos um breve recorte sobre os marcos legais da trajetória da Extensão Universitária no Brasil, a partir de 1987, marcos esses significativos e indispensáveis para que as Instituições de Educação Superior cumpram seu papel social por meio da execução de práticas/ações extensionistas que venham suprir as possíveis demandas de desigualdades sociais existentes. 


\section{Práticas Extensionistas no Contexto da Proex/Unitins: janeiro de 2019 a março de 2020}

Considerando que a "educação é um direito de todos" (CF/1988) e que a universidade é o local capaz de transformar sonhos em realidade, bem como de contribuir para a superação de contextos sociais de desigualdades e exclusão, este momento do trabalho destina-se às apresentações de algumas das ações extensionistas desenvolvidas no âmbito da Pró-Reitoria de Extensão, Cultura e Assuntos Comunitários da Universidade Estadual do Tocantins (Proex/Unitins), durante o período que compreende os meses de janeiro de 2019 e março de 2020.

\section{Contribuições em tempos de mudanças no sistema educacional}

Nesse contexto, verifica-se que, em tempos de mudanças no sistema educacional, a Extensão Universitária desempenha um papel fundamental na comunidade acadêmica e externa à universidade, pois possibilita a socialização e democratização do conhecimento adquirido e a promoção de ações em benefício de segmentos mais vulneráveis.

Por meio de programas, projetos, cursos e eventos extensionistas, a instituição chega até a comunidade para beneficiá-la de alguma forma, oferecendo ao aluno a possibilidade de colocar em prática o conhecimento aprendido durante a graduação e, consequentemente, de ganhar experiência na carreira escolhida, enquanto presta um serviço à sociedade.

Assim, pautadas na formação do aluno, disseminação de conhecimentos e contribuição social, relevantes ações extensionistas foram desenvolvidas no âmbito da Pró-reitoria de Extensão, Cultura e Assuntos Comunitários da Unitins. A seguir, pontuam-se informações de alguns dos projetos extensionistas, executados durante o período de janeiro de 2019 a março de 2020: 
QUADRO 1: Promovendo saúde e bem-estar social a partir de uma alimentação saudável

\begin{tabular}{|c|c|c|}
\hline Ação/Projeto & Objetivo & Contribuições \\
\hline $\begin{array}{c}\text { "Promovendo saúde } \\
\text { e bem-estar social a } \\
\text { partir de uma } \\
\text { alimentação } \\
\text { saudável" } \\
\text { Coordenadores: } \\
\text { Joelson de Araújo } \\
\text { Delfino e Arison José } \\
\text { Pereira } \\
\text { Câmpus Palmas } \\
\text { Proex/Unitins }\end{array}$ & $\begin{array}{l}\text { Com o intuito de fortalecer a } \\
\text { agricultura urbana, estimular } \\
\text { a adoção de hábitos saudáveis, } \\
\text { valorizar a cultura e o } \\
\text { conhecimento popular, bem } \\
\text { como os vínculos na } \\
\text { comunidade, este projeto de } \\
\text { extensão voltou-se à } \\
\text { implantação de uma horta } \\
\text { comunitária no "Lar de Idosos } \\
\text { Tia Angelina", localizado na } \\
\text { cidade de Porto Nacional-TO. }\end{array}$ & $\begin{array}{l}\text { O projeto "Promovendo saúde e bem- } \\
\text { estar social a partir de uma } \\
\text { alimentação saudável", realizado no } \\
\text { Lar de Idosos Tia Angelina, município de } \\
\text { Porto Nacional-TO, proporcionou grandes } \\
\text { benefícios tanto para os idosos, como } \\
\text { para os servidores do Lar e para os } \\
\text { integrantes do projeto. A produção da } \\
\text { horta serviu para alimentar os idosos e } \\
\text { melhorou a qualidade das refeições, pois } \\
\text { as hortaliças produzidas são alimentos de } \\
\text { qualidade sem nenhum tipo de } \\
\text { agrotóxico, ricos em vitaminas e sais } \\
\text { minerais, nutrientes essenciais para o } \\
\text { perfeito funcionamento do organismo e } \\
\text { promotores de assimilação de outros } \\
\text { nutrientes. Já os alunos, além da } \\
\text { interação social e a convivência com as } \\
\text { pessoas idosas, tiveram a oportunidade } \\
\text { de colocar em prática os conhecimentos } \\
\text { adquiridos nas aulas da disciplina de } \\
\text { Olericultura, desenvolvendo e e } \\
\text { participando de todas as etapas do } \\
\text { cultivo, sob a orientação do professor } \\
\text { coordenador do projeto. }\end{array}$ \\
\hline
\end{tabular}

Fonte: Projeto-Promovendo saúde e bem-estar social a partir de uma alimentação saudável/Proex/Unitins/2019.

O projeto de extensão "Promovendo saúde e bem-estar social a partir de uma alimentação saudável”, realizado no Lar de Idosos Tia Angelina, no município de Porto Nacional - TO, é uma ação de relevância social, pois a sua concretização proporcionou benefícios para a saúde das pessoas idosas, como qualidade de vida e bem-estar, ao terem a oportunidade de se alimentar de verduras e legumes frescos e saudáveis diariamente.

Entre os beneficiados estão: 41 (quarenta e uma) pessoas do "Lar de Idosos Tia Angelina”, sendo 20 (vinte) idosos e 21 (vinte e um) servidores que vivem no Lar, além dos integrantes do projeto (alunos, professores e técnicos da Proex), perfazendo um total de aproximadamente 50 (cinquenta) pessoas.

Para o coordenador Delfino (2020), "os alunos do curso de Engenharia Agronômica da Unitins - Câmpus Palmas, integrantes do projeto, tiveram a oportunidade de compreender a importância de uma 
alimentação de qualidade e desenvolver de forma interdisciplinar conteúdo das diversas áreas do conhecimento do curso". O professor destaca, ainda, que esta ação promoveu mudanças de postura e de percepção de responsabilidade nos alunos participantes.

Ações extensionistas como esta fortalecem a integração social, os vínculos entre a comunidade acadêmica, alunos e idosos, proporcionando mudanças significativas nas suas vidas, resgatando a cidadania, melhorando a qualidade de vida, elevando a autoestima, possibilitando alegria e satisfação.

QUADRO 2: Um Olhar para a Preservação dos Quelônios no Tocantins

\begin{tabular}{|c|c|c|}
\hline Ação/Projeto & Objetivo & Contribuições \\
\hline $\begin{array}{c}\text { Projeto "Um Olhar } \\
\text { para a Preservação } \\
\text { dos Quelônios no } \\
\text { Tocantins" } \\
\text { Coordenadores: } \\
\text { Alessandra Ruita Santos } \\
\text { Czapski e Marcus } \\
\text { Vinícius Moreira Barbosa } \\
\text { Proex/Unitins } \\
\text { Palmas-TO }\end{array}$ & $\begin{array}{l}\text { As ações de extensão e } \\
\text { pesquisa desse projeto } \\
\text { estiveram focadas na } \\
\text { preservação das espécies de } \\
\text { quelônios, por meio de } \\
\text { oficina de conscientização } \\
\text { ambiental e reciclagem de } \\
\text { lixo, objetivando } \\
\text { sensibilizar, provocar } \\
\text { discussões e suscitar o } \\
\text { envolvimento } \\
\text { comunidade em geral na } \\
\text { proteção, preservação e } \\
\text { conservação das espécies de } \\
\text { quelônios tão importantes } \\
\text { para o equilíbrio ecológico. }\end{array}$ & 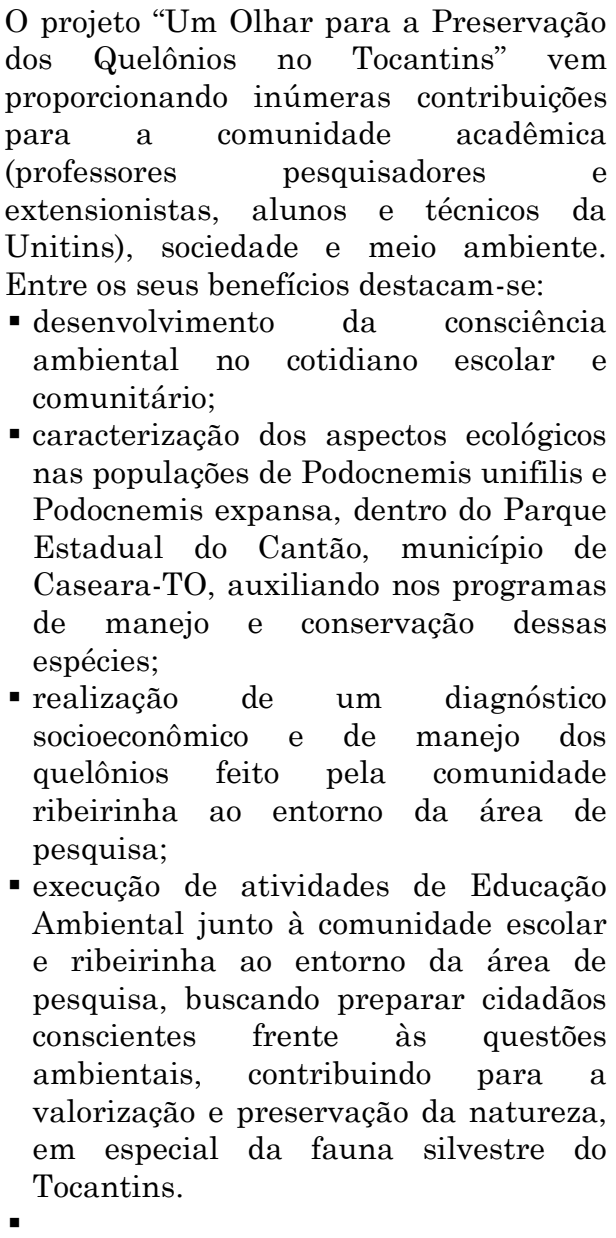 \\
\hline
\end{tabular}

Fonte: Projeto-Um Olhar para a Preservação dos Quelônios no Tocantins/Proex/Unitins/2019.

O Projeto "Um Olhar para a Preservação dos Quelônios no Tocantins"

é uma iniciativa de grande valor social e ambiental, pois, além da 
conscientização no que diz respeito à preservação do meio ambiente, colabora com o repovoamento de espécies nativas que estão ameaçadas de extinção. Para a coordenadora Alessandra dos Santos Czapski (2020), o projeto "contribui significativamente para a formação do aluno, pois proporciona, com a prática, uma nova visão sobre educação ambiental e a importância da preservação dos quelônios. Além da interação com o meio ambiente de forma lúdica, o aluno tem a possibilidade de buscar, aprofundar, compartilhar e produzir conhecimentos científicos”.

A ação extensionista beneficiou até o momento mais de 100 (cem) alunos das escolas da rede pública de Caseara-TO, por meio das atividades de educação ambiental. Também são público-alvo do projeto a população ribeirinha, moradores de assentamentos e população local.

\section{QUADRO 3: Cine-Escola/Cine-Ciência}

\begin{tabular}{|c|c|c|}
\hline Ação/Projeto & Objetivo & Contribuições \\
\hline $\begin{array}{c}\text { Cine-Escola/Cine- } \\
\text { Ciência } \\
\text { Coordenadores: } \\
\text { Leila Dias Pereira do } \\
\text { Amaral e Vinícius } \\
\text { Carvalho da Silva } \\
\\
\text { Proex/Unitins } \\
\text { Palmas-TO }\end{array}$ & $\begin{array}{l}\text { Tratam-se de dois projetos de } \\
\text { extensão. O Cine-Escola: Luz, } \\
\text { Câmera, Educação é } \\
\text { vinculado ao Programa de } \\
\text { Extensão "Núcleo de Estudos } \\
\text { em Direitos Humanos - } \\
\text { NEDIH" e visa, por meio de } \\
\text { exibição de filmes, debater } \\
\text { junto aos estudantes de } \\
\text { escolas públicas temas } \\
\text { diversificados a partir da } \\
\text { ótica dos direitos humanos. O } \\
\text { Cine-Ciência, por sua vez, é } \\
\text { um projeto que integra o } \\
\text { programa extensionista } \\
\text { UniCidade, vinculado à Pró- } \\
\text { reitoria de Pesquisa e Pós- } \\
\text { Graduação. } \\
\text { Durante o ano de 2019, os } \\
\text { dois projetos foram } \\
\text { executados em parceria, com } \\
\text { o objetivo de suscitar debates } \\
\text { sobre os direitos humanos, } \\
\text { promover o ensino da ciência, } \\
\text { tecnologia e inovação, focado } \\
\text { na educação informal e na } \\
\text { popularização da ciência para } \\
\text { toda sociedade. }\end{array}$ & $\begin{array}{l}\text { A ação extensionista "Cine-Escola/Cine- } \\
\text { Ciência contemplou estudantes de Ensino } \\
\text { Médio das Escolas Estaduais Criança } \\
\text { Esperança e São José e do Instituto Federal de } \\
\text { Educação, Ciência e Tecnologia do Tocantins } \\
\text { (IFTO), que assistiram ao filme "Estrelas além } \\
\text { do tempo" e, na sequência, debateram sobre } \\
\text { luta das mulheres, diversidade, racismo e } \\
\text { ciência, sempre em consonância com a } \\
\text { temática dos direitos humanos. } \\
\text { Os momentos de exibição e debates sobre o } \\
\text { aludido filme, além de terem contribuído com } \\
\text { a promoção da consciência em direitos } \\
\text { humanos e da ciência a partir da } \\
\text { universidade, mostraram aos alunos o quanto } \\
\text { é necessária força de vontade, determinação e } \\
\text { foco para se alcançar objetivos. } \\
\text { A ação beneficiou diretamente alunos e } \\
\text { professores, sendo: cerca de } 40 \text { (quarenta) } \\
\text { alunos do Colégio Estadual Criança } \\
\text { Esperança; 35 (trinta e cinco) alunos do } \\
\text { Colégio Estadual São José, cerca de } 60 \\
\text { (sessenta) alunos do Instituto Federal de } \\
\text { Educação, Ciência e Tecnologia do Tocantins- } \\
\text { IFTO e integrantes dos projetos, perfazendo } \\
\text { um total de aproximadamente 140 pessoas }\end{array}$ \\
\hline
\end{tabular}

Fonte: Projeto-Cine-Escola/Cine-Ciência/Proex/Unitins/2019. 
A ação Cine-Escola/Cine-Ciência oportunizou uma experiência de transformação, no sentido de melhorar o ambiente escolar em relação à sociedade, "promovendo igualdade e integração com a mesma, na intenção de diminuir a discriminação, a violência, a intolerância e o preconceito", conforme destaca a professora Leila Amaral (2019), uma das responsáveis pela ação.

O filme "Estrelas além do tempo" suscita debates sobre a inserção da mulher na pesquisa, preconceitos de gênero e étnico-racial e a parceria dos projetos Cine-Escola e Cine-Ciência, segundo os seus coordenadores à época, buscou abordar a ciência como um direito humano fundamental e como os direitos humanos, ao longo da história do pensamento científico, foram violados em diversos episódios.

QUADRO 4: Sobre Todas Elas

\begin{tabular}{|c|c|c|}
\hline Ação/Projeto & Objetivo & Contribuições \\
\hline $\begin{array}{c}\text { “Sobre Todas Elas" } \\
\text { Coordenadora: } \\
\text { Lilian Natália Ferreira } \\
\text { de Lima } \\
\text { Câmpus Augustinópolis } \\
\text { Proex/Unitins }\end{array}$ & $\begin{array}{l}\text { Promover } \\
\text { enfrentamento ativo da } \\
\text { violência contra a } \\
\text { mulher nos diferentes } \\
\text { âmbitos nos quais a } \\
\text { figura feminina está } \\
\text { inserida. }\end{array}$ & $\begin{array}{l}\text { O projeto "Sobre Todas Elas", realizado } \\
\text { em instituições públicas de ensino dos } \\
\text { municípios de Augustinópolis-TO e } \\
\text { Araguatins-TO, consiste em uma ação de } \\
\text { grande relevância social, pois até o momento } \\
\text { foi possível sensibilizar o público-alvo quanto } \\
\text { a importância da identificação e do combate } \\
\text { à violência contra a mulher dentro das } \\
\text { escolas, no espaço público, nos próprios lares } \\
\text { e demais locais onde a mesma possa ser } \\
\text { observada. } \\
\text { Durante o período de janeiro de } 2019 \text { a } \\
\text { março de } 2020 \text { foi possível observar a } \\
\text { dificuldade de muitos alunos em identificar } \\
\text { determinadas facetas da violência de gênero, } \\
\text { especialmente a psicológica e a de cunho } \\
\text { sexual. Todas as atividades contribuíram } \\
\text { para desnaturalizar, dentro do espaço de } \\
\text { debate, as condutas violentas legitimadas } \\
\text { pela sociedade em virtude do contexto } \\
\text { cultural historicamente construído. } \\
\text { Essa ação beneficiou alunos, professores e } \\
\text { gestores de instituições públicas de ensino de } \\
\text { Augustinópolis-TO e Araguatins-TO. }\end{array}$ \\
\hline
\end{tabular}

Fonte: Projeto-Sobre Todas Elas/Proex/Unitins/2019.

A professora Lilian Lima (2020), coordenadora do Projeto de Extensão, destaca que a realização do "Sobre Todas Elas" estimulou a 
quebra do silêncio desse problema que afeta tantas mulheres, não só na região do Bico do Papagaio, mas em todo o território nacional e mundial.

Por meio do projeto foram desenvolvidas ações de sensibilização sobre a importância da identificação e do combate à violência contra a mulher dentro das escolas, no espaço público, nos próprios lares e demais locais onde a mesma possa ser observada.

Lima (2020) destaca que os adolescentes/alunos, benefiários diretos do projeto, tornaram-se aliados e replicadores do conhecimento, entendendo que a mudança sócio cultural, apesar de lenta, acontece quando a cada dia mais pessoas são alcançadas e engajam-se no enfrentamento dos problemas naturalizados na sociedade.

QUADRO 5: Cuidando do Cuidador

\begin{tabular}{|c|c|c|}
\hline Projeto/Ação & Objetivo & Contribuições \\
\hline $\begin{array}{c}\text { "Cuidando do } \\
\text { Cuidador" } \\
\text { Coordenadora: } \\
\text { Janayna Araújo Viana } \\
\text { Câmpus Augustinópolis } \\
\text { Proex/Unitins }\end{array}$ & $\begin{array}{l}\text { Este projeto teve como } \\
\text { objetivo } \\
\text { exercícios laborais e } \\
\text { orientações em saúde na } \\
\text { prevenção de riscos } \\
\text { ergonômicos } \\
\text { profissionais atuantes nara } \\
\text { creche Epermina Ferreira } \\
\text { de Almeida, no município } \\
\text { de Augustinópolis-TO. }\end{array}$ & $\begin{array}{l}\text { O projeto extensionista "Cuidando do } \\
\text { Cuidador", realizado na creche Epermina } \\
\text { Ferreira de Almeida, município de } \\
\text { Augustinópolis - TO, proporcionou uma } \\
\text { série de benefícios, tanto para os } \\
\text { funcionários da Creche, como para os } \\
\text { integrantes do projeto. Entre as } \\
\text { contribuições destacam-se: a melhora na } \\
\text { flexibilidade dos participantes na hora dos } \\
\text { exercícios de ginástica laboral; uma maior } \\
\text { disposição para o trabalho ao longo do dia } \\
\text { e semana; bom humor e bons } \\
\text { relacionamentos dentro do ambiente de } \\
\text { trabalho; maior proximidade entre os } \\
\text { participantes e diminuição do } \\
\text { sedentarismo dos mesmos, uma vez que, } \\
\text { incentivados pelo projeto, vêm buscando } \\
\text { praticar atividades físicas para uma } \\
\text { melhor qualidade de vida. }\end{array}$ \\
\hline
\end{tabular}

Fonte: Projeto-Cuidando do Cuidador/Proex/Unitins/2019.

Segundo a Coordenadora Janayna Viana e a aluna Gonçalves (2020, p. 5), o Projeto de Extensão "Cuidando do Cuidador" despertou um olhar diferenciado sobre a importância de se trabalhar a saúde do trabalhador junto à comunidade externa, por meio da extensão universitária. 
Há de se destacar que as informações obtidas com o projeto também servirão de base para relatórios e artigos científicos. Logo, a ação de educação em saúde, além de proporcionar reflexões e os benefícios supracitados, vêm resultando em dados que podem contribuir para a melhoria da qualidade de vida dos colaboradores da Creche Municipal "Permina Ferreira de Almeida", assim como para a vida dos alunos e professores integrantes desse projeto.

Entre os beneficiados estão: 31 (trinta e um) funcionários da Creche e mais os integrantes do projeto, perfazendo um total de 34 (trinta e quatro) pessoas beneficiadas nessa ação.

QUADRO 6: Cidadão nota 10

\begin{tabular}{|c|c|c|}
\hline Ação/Projeto & Objetivo & Contribuições \\
\hline $\begin{array}{c}\text { “Cidadão nota 10” } \\
\text { Coordenador: } \\
\text { Irineu wagner Junior } \\
\text { Valoais } \\
\text { Câmpus Augustinópolis } \\
\text { Proex/Unitins }\end{array}$ & $\begin{array}{l}\text { Promover a aplicação dos } \\
\text { conhecimentos sobre os } \\
\text { Direitos Fundamentais e } \\
\text { Educação } \\
\text { Básica, a fim de que os } \\
\text { participantes se emancipem } \\
\text { enquanto } \\
\text { brasileiros. }\end{array}$ & $\begin{array}{l}\text { Possibilitando aos acadêmicos uma } \\
\text { interação com a comunidade local, o } \\
\text { projeto promove aos alunos do curso de } \\
\text { Direito uma formação específica sobre } \\
\text { os Direitos Fundamentais, e aos alunos } \\
\text { de Ciências Contábeis uma formação } \\
\text { específica sobre Educação Financeira } \\
\text { Pessoal, bem como os habilita a falar } \\
\text { em público, a partir da interação com } \\
\text { alunos do ensino fundamental dos } \\
\text { municípios da região do Bico do } \\
\text { Papagaio. } \\
\text { Os conhecimentos sobre Direitos } \\
\text { Fundamentais e Educação financeira, } \\
\text { durante o período de janeiro de 2019 a } \\
\text { março de 2020 foram compartilhados } \\
\text { com os alunos de algumas escolas dos } \\
\text { seguintes municípios: Axixá-TO, Buriti- } \\
\text { TO, Praia Norte-TO, São Sebastião, } \\
\text { Augustinópolis-TO, Povoado Dezesseis } \\
\text { (Augustinópolis). }\end{array}$ \\
\hline
\end{tabular}

Fonte: Projeto-Cidadão Nota 10/Proex/Unitins/2019.

Conforme exposto no relatório do coordenador Irineu Valoais e aluna Santos (2020, p. 4), o projeto “Cidadão nota 10", além de contribuir com a formação profissional dos alunos dos cursos de Direito e Ciências Contábeis - Câmpus Augustinópolis, beneficia alunos e professores das escolas do Ensino Fundamental dos municípios da Região do Bico do Papagaio (Zona Rural e Urbana). 
QUADRO 6: Discursos, narrativas e poemas quilombolas do Tocantins

\begin{tabular}{|c|c|c|}
\hline Ação/Projeto & Objetivo & Contribuições \\
\hline $\begin{array}{c}\text { "Discursos, narrativas e } \\
\text { poemas quilombolas do } \\
\text { Tocantins" } \\
\text { Coordenadora: } \\
\text { Luama Socio }\end{array}$ & $\begin{array}{l}\text { Objetiva ampliar as atividades } \\
\text { universitárias em direção à } \\
\text { comunidade, capacitando os } \\
\text { acadêmicos na construção e } \\
\text { execução de um projeto, desde } \\
\text { as etapas conceituais até o } \\
\text { momento de compartilhamento } \\
\text { dos resultados com o público. } \\
\text { Isto posto, a meta é promover a } \\
\text { escuta de discursos, narrativas } \\
\text { e poemas de integrantes do } \\
\text { Quilombo da Ilha de São } \\
\text { Vicente, realizando o registro e } \\
\text { transcrição dessa literatura de } \\
\text { caráter oral em suportes } \\
\text { escrito e audiovisual e } \\
\text { posterior compartilhamento } \\
\text { com a comunidade em geral, } \\
\text { com alunos da rede pública de } \\
\text { ensino de Araguatins-TO, mais } \\
\text { especificamente, e com o } \\
\text { público difuso das plataformas } \\
\text { digitais. }\end{array}$ & $\begin{array}{l}\text { Com a colaboração do coordenador } \\
\text { do curso de Letras, Victor Borges, do } \\
\text { fotógrafo e videomaker Walter } \\
\text { Antunes (colaboração externa) e do } \\
\text { bolsista do Programa Institucional } \\
\text { de Bolsas de Iniciação à Extensão - } \\
\text { pibiex, Léo Daniel da Conceição, o } \\
\text { trabalho resultou em textos de } \\
\text { caráter poético e documental } \\
\text { (literários), que foram publicados } \\
\text { em versão escrita e audiovisual no } \\
\text { site www.historiasdailha.com, com } \\
\text { vistas à preservação integral dos } \\
\text { discursos e falas originais dos } \\
\text { quilombolas participantes. Entre os } \\
\text { dias } 1^{\circ} \text { de dezembro de } 2019 \text { e } 18 \text { de } \\
\text { fevereiro de } 2020 \text {, a plataforma } \\
\text { digital obteve } 1.173 \text { (mil cento e } \\
\text { setenta e três) visitas. }\end{array}$ \\
\hline
\end{tabular}

Fonte: Projeto - Discursos, Narrativas e Poemas Quilombolas do Tocantins/Proex/Unitins/2019.

Até o momento, o referido projeto contou com a participação de alunos do curso de Letras - Câmpus Araguatins, que foram selecionados para colaborar nas etapas de confecção de livro manual e divulgação. Durante os meses de agosto, setembro e outubro do ano de 2019 foram realizados seis encontros com membros do Quilombo Ilha de São Vicente e, concomitantemente, realizadas entrevistas semi-diretivas, escutas e registros de histórias ao longo dessas visitas, conforme relata a coordenadora do projeto, professora Luama Socio (2019).

Para a coordenadora (2019, p. 2), do ponto de vista literário, esta etapa foi importante pelo fato de agregar à publicação a modalidade diretamente oral da atividade de "contar histórias", bem como por preservar o registro visual e gestual dos próprios contadores dessas histórias.

Por fim, como previsto no projeto e evidenciado em seu relatório parcial, a equipe de trabalho, com a colaboração dos alunos, confeccionou 
cerca de 100 (cem) exemplares de um livro artesanal, contendo excertos das histórias integrantes do site. Os livros foram distribuídos entre os próprios quilombolas que não têm acesso à internet, como uma forma de entrarem em contato com os resultados do trabalho.

QUADRO 7: Liga Acadêmica de Direitos Humanos: difusão de conhecimentos acerca dos Direitos Humanos

\begin{tabular}{|c|c|c|}
\hline Ação/Projeto & Objetivo & Contribuições \\
\hline $\begin{array}{c}\text { "Liga Acadêmica de } \\
\text { Direitos Humanos: } \\
\text { difusão de } \\
\text { conhecimentos acerca } \\
\text { dos Direitos Humanos" } \\
\text { Coordenadoras: } \\
\text { Zilmária Aires dos Santos e } \\
\text { Beatriz Cilene Mafra } \\
\text { Neves } \\
\text { CâmpusDianópolis } \\
\text { Proex/Unitins }\end{array}$ & $\begin{array}{l}\text { Objetiva promover a } \\
\text { difusão dos direitos e } \\
\text { garantias fundamentais } \\
\text { no meio acadêmico e } \\
\text { social, com foco } \\
\text { específico entre alunos } \\
\text { do ensino médio das } \\
\text { escolas públicas } \\
\text { existentes no Município } \\
\text { e região do Sudeste } \\
\text { Tocantinense. }\end{array}$ & $\begin{array}{l}\text { O projeto "Liga Acadêmica de Direitos } \\
\text { Humanos: difusão de conhecimentos } \\
\text { acerca dos Direitos Humanos", } \\
\text { direcionado aos acadêmicos e alunos do } \\
\text { ensino médio de escolas públicas, tem } \\
\text { obtido resultados positivos junto ao } \\
\text { munícipio e região do Sudeste } \\
\text { Tocantinense, uma vez que as atividades } \\
\text { desenvolvidas têm o intuito de promover a } \\
\text { difusão de conhecimentos acerca dos } \\
\text { direitos fundamentais humanos no } \\
\text { ambiente acadêmico e social de forma } \\
\text { inovadora, visando a integração e a } \\
\text { socialização dos saberes científicos e } \\
\text { culturais dos povos. Durante as ações } \\
\text { realizadas até o momento, observou-se o } \\
\text { grande interesse do público-alvo sobre os } \\
\text { temas trabalhados e que o ambiente } \\
\text { acadêmico é campo ideal para realização de } \\
\text { ações desta natureza. }\end{array}$ \\
\hline
\end{tabular}

Fonte: Projeto - Liga Acadêmica de Direitos Humanos: difusão de conhecimentos acerca dos Direitos Humanos /Proex /Unitins/2019.

Segundo relatório apresentado pela coordenadora Zilmária Santos e aluna Nascimento (2020), o Projeto "Liga Acadêmica de Direitos Humanos: difusão de conhecimentos acerca dos Direitos Humanos” desenvolveu, em 2019, palestras sobre "O que é direito humano?" e roda de conversa sobre violações de direitos humanos e novas tecnologias digitais, abordando a origem, abrangência, definição, características e denominadas gerações dos direitos humanos, além das formas de internacionalização e internalização desses direitos no plano interno, os sistemas global e regionais de proteção.

Em 2020 foi realizada roda de conversa com o tema "O que é ser mulher?", com discussões pautadas na violação de direitos das mulheres e 01 (uma) aula aberta com o tema "Violação de Direitos Humanos e novas tecnologias digitais". 
Foram beneficiados com as ações professores, alunos da Unitins e do ensino médio das escolas públicas existentes no município e região do Sudeste Tocantinense.

QUADRO 8: Conte-me mais: práticas de letramento literário no Ensino Fundamental

\begin{tabular}{|c|c|c|}
\hline Ação/Projeto & Objetivo & Contribuições \\
\hline $\begin{array}{l}\text { “Conte-me mais: } \\
\text { práticas de letramento } \\
\text { literário no Ensino } \\
\text { Fundamental” } \\
\text { Coordenadora: } \\
\text { Elem Kássia Gomes } \\
\\
\text { Câmpus Araguatins } \\
\text { Proex/Unitins }\end{array}$ & $\begin{array}{lr}\text { Teve como objetivo } \\
\text { incentivar a formação } \\
\text { de leitores literários, } \\
\text { otimizando } \\
\text { competência de leitura e } \\
\text { interpretação de textos } \\
\text { por parte dos alunos } \\
\text { participantes do } 5^{\circ} \text { ano, } \\
\text { do Ensino } \\
\text { Fundamental, na } \\
\text { perspectiva na do } \\
\text { letramento literário. }\end{array}$ & $\begin{array}{l}\text { O projeto "Conte-me mais: práticas de } \\
\text { letramento literário para o ensino } \\
\text { fundamental" foi realizado em uma } \\
\text { escola municipal da cidade de Araguatins- } \\
\text { TO, atendendo ao } 5^{\circ} \text { ano do ensino } \\
\text { fundamental. Embora alguns dos objetivos } \\
\text { previstos não tenham sido totalmente } \\
\text { atingidos, o projeto trouxe uma importante } \\
\text { contribuição social, pois os resultados } \\
\text { alcançados são bastante satisfatórios. Ao } \\
\text { longo das oficinas foi possível observar a } \\
\text { evolução e a motivação dos alunos para a } \\
\text { realização das atividades, o interesse em } \\
\text { frequentar as aulas assiduamente, e, } \\
\text { ainda, os laços afetivos criados com as } \\
\text { crianças do projeto foram estreitados. } \\
\text { Durante o desenvolvimento da ação, além } \\
\text { dos professores, alunos e integrantes do } \\
\text { projeto, foram beneficiados alunos do } 5^{\circ} \\
\text { ano do ensino fundamental de uma escola } \\
\text { municipal da cidade de Araguatins-TO. }\end{array}$ \\
\hline
\end{tabular}

Fonte: Projeto Conte-me mais: práticas de letramento literário no Ensino Fundamental - Proex /Unitins/2019.

No tocante à prática extensionista "Conte-me mais: práticas de letramento literário no Ensino Fundamental", a coordenadora Elem Gomes e aluna Azevedo (2020, p. 16) expõem em relatório em que os resultados alcançados com o projeto, apesar de simples, caracterizaram-se como um prenúncio de mudança em relação à ausência do hábito da leitura. Com a prática, observou-se que há uma falta de acesso, por parte dos alunos, aos livros literários e que, na maioria das vezes, há também falta de livros nas próprias escolas.

Verifica-se, pelo relatório, que o adequado letramento literário tem um papel indispensável na formação de alunos/leitores, justamente por oferecer estratégia metodológica no direcionamento e fortalecimento do ensino de literatura, possibilitando a aproximação entre literatura e leitores e ampliando as possibilidades de interpretação do mundo narrado e do mundo vivido. 


\section{Conclusão}

Ante o exposto, acreditamos que esta retrospectiva apresentou um pouco das ações extensionistas desenvolvidas no contexto da Proex/Unitins, no período de janeiro de 2019 a março de 2020, revelando os benefícios para a formação profissional e pessoal dos envolvidos, e as contribuições da extensão universitária para superação das desigualdades sociais em tempos de mudanças educacionais.

Assim, resta evidente que a Pró-reitoria de Extensão, Cultura e Assuntos Comunitários da Universidade Estadual do Tocantins (Proex/Unitins) tem incentivado práticas extensionistas em prol dos alunos e comunidade externa, por meio das quais os alunos colocam em prática os conhecimentos adquiridos em sala de aula, desenvolvem a criatividade, melhoram as relações interpessoais que cooperam de forma significativa com a sua formação e transformação de espaços sociais, especialmente os mais vulneráveis.

Para Almeida (2012, p. 58), com a extensão, "o estudante passa a mudar sua postura frente ao outro, mudando atitudes, valores e compreendendo seu papel enquanto profissional do amanhã”. Nessa esteira, é importante destacar as palavras de Fernandes (2011, p. 141), quando diz que:

[...] a extensão universitária traz para estudantes e professores a oportunidade da convivência e o envolvimento com realidades sociais diferentes de outras culturas, o que instiga à formulação de novas interrogações sobre a dinâmica das relações sociais, sobre os problemas sócio-econômicos do País, sobre a cultura nacional e local e sobre a questão da solidariedade, questões essas que poderão ser concretizadas em discussões ampliadas na universidade, através de pesquisa e no ambiente da sala de aula.

Por fim, é possível depreender do estudo realizado, que a Proex/Unitins tem procurado inovar e estimular a efetivação de programas, projetos, cursos e eventos extensionistas junto à comunidade acadêmica e externa, como forma de integração, socialização e superação das desigualdades sociais. 


\section{Referências}

BRASIL. Lei $n^{\circ}$ 9.393, de 20 de dezembro de 1996. Estabelece as diretrizes e bases da educação nacional. Brasília, DF: Presidência da República, 1996. Disponível em: http://www.planalto.gov.br/ccivil 03/leis/19394.htm. Acesso em:10 set. 2020.

BRASIL. Lei $n^{\circ}$ 10.172, de 9 de janeiro de 2001. Aprova o Plano Nacional de Educação e dá outras providências. Brasília, DF: Presidência da República, 2001. Disponível em:

http://www.planalto.gov.br/ccivil 03/leis/leis 2001/110172.htm. Acesso em: 11 set. 2020 .

BRASIL. Lei $n^{\circ} 13.005$, de 25 de junho de 2014. Aprova o Plano Nacional de Educação - PNE e dá outras providências. Brasília, DF: Presidência da República, 2014. Disponível em:

http://www.planalto.gov.br/ccivil 03/ ato2011-2014/2014/lei/l13005.htm. Acesso em: 11 set. 2020.

CASTRO, L. M. C. A universidade, a extensão universitária e a produção de conhecimentos emancipadores. In: REUNIÃO ANUAL DA ANPED, 27, Caxambu, 2004. Anais... Caxambu: ANPEd, 2004. Disponível em: http://27reuniao.anped.org.br/gt11/ t1111.pdf. Acesso em: 01 de out. 2020

DEMO, P. Introdução a Metodologia da Ciência. 2. Ed. São Paulo: Atlas, 1985. Disponível em:

http://maratavarespsictics.pbworks.com/w/file/fetch/74301206/DEMOIntroducao-a-Metodologia-da-Ciencia.pdf. Acesso em: 11 set. 2020.

DEMO, P. Pesquisa e construção de conhecimento: metodologia científica no caminho de Habermas. 7.ed. Rio de Janeiro: Tempo Brasileiro, 2009a.

DEMO, P. O lugar da extensão. In: (Org.). FARIAS, D. S. Construção conceitual da extensão universitária na América Latina. Brasília: Ed. UnB, 2001.

DEMO, P. Pesquisa: princípio científico e educativo. 12. Ed. São Paulo: Cortez, 2006, 128p.

FERNANDES, Mônica Abranches. Trabalho comunitário: uma metodologia para ação coletiva e educativa da extensão universitária em comunidades. In: MENEZES, Ana Luiza Teixeira; SÍVERES, Luiz (Orgs.).Transcendendo fronteiras: a contribuição da extensão nas instituições comunitárias de ensino superior. Santa Cruz do Sul-SC: Edunisc, 2011. p. 138-157.

I FORPROEX - Encontro de Pró-Reitores de Extensão das Universidades Públicas Brasileiras, 1987, Brasília. Conceito de extensão, institucionalização e financiamento. Disponível em: https://www2.unifap.br/dex/files/2015/04/1987-I-Encontro-Nacional-doFORPROEX.pdf. Acesso em: 10 set. 2020. 
FÓRUM NACIONAL DE EXTENSÃO E AÇÃO COMUNITÁRIA DAS UNIVERSIDADES E INSTITUIÇÕES EE ENSINO SUPERIOR COMUNITÁRIAS - FOREXT. Carta de Goiânia. 1999. Disponível em: http://www.uniso.br/forext/documentos.asp. Acesso em: 10 set. 2020.

FÓRUM NACIONAL DE EXTENSÃO E AÇÃO COMUNITÁRIA DAS UNIVERSIDADES E INSTITUIÇÕES E ENSINO SUPERIOR COMUNITÁRIAS - FOREXT. 2001, Recife. Anais eletrônicos... Disponível em: https://www.ufmg.br/proex/renex/. Acesso em: 10 set. 2020

FÓRUM DE PRÓ-REITORES DE EXTENSÃO DAS UNIVERSIDADES PÚBLICAS BRASILEIRAS - FORPROEX. Indissociabilidade ensinopesquisa-extensão e a flexibilização curricular: uma visão da extensão. Brasília: MEC/SESu, 2006.

FÓRUM DE PRÓ-REITORES DE EXTENSÃO DAS UNIVERSIDADES PÚBLICAS BRASILEIRAS - FORPROEX. Política Nacional de Extensão Universitária. Manaus. Maio/2012. Disponível em:

https://proex.ufsc.br/files/2016/04/Pol\%C3\%ADtica-Nacional-deExtens\%C3\%A3o-Universit\%C3\%A1ria-e-book.pdf. Acesso em: 20 set. 2020.

FÓRUM DE PRÓ-REITORES DE EXTENSÃO DAS INSTITUIÇÕES PÚBLICAS DE EDUCAÇÃO SUPERIOR BRASILEIRAS. Comissão Permanente de Avaliação da Extensão. Avaliação da Extensão Universitária: práticas e discussões da Comissão Permanente de Avaliação da Extensão / Organização: Maria das Dores Pimentel Nogueira; textos: Sonia Regina Mendes dos Santos ... [et al.] - Belo Horizonte: FORPROEX/CPAE; PROEX/UFMG, 2013. Disponível em: http://uemg.br/downloads/Avaliacao\%20da\%20Extensao\%20Universitaria\%20livro\%208.pdf. Acesso em: 15 set. 2020.

FREIRE, P. Extensão ou Comunicação? 12.ed. Rio de Janeiro: Paz e Terra, 1977.

NOGUEIRA, M. das D. P. (Org.). Extensão universitária: diretrizes conceituais e políticas. Documentos básicos do Fórum Nacional de PróReitores de Extensão das Universidades Públicas Brasileiras. 1987-2000. Belo Horizonte: PROEX/UFMG, 2000, 194 p.

NOGUEIRA, M. das D. P. (Org.). Extensão universitária no Brasil: uma revisão conceitual. In: FARIAS, D. S. (Org.) Construção conceitual da extensão universitária na América Latina. Brasília: Editora da UNB, 2001. p. 57-72.

RENEX - Rede Nacional de Extensão. Política Nacional de Extensão Áreas Temáticas. Disponível em: https://www.ufmg.br/proex/renex/. Acesso em: 15 set. de 2020. 
SANTOS, B. S. A universidade no século XXI: para uma reforma democrática e emancipatória da universidade. São Paulo: Cortez, 2004. (Coleção Questões da Nossa Época, v. 11)

SÍVERES, Luiz. Princípios estruturantes da extensão universitária. In: MENEZES, Ana Luiza Teixeira (Orgs.).Transcendendo fronteiras: a contribuição da extensão nas instituições comunitárias de ensino superior.Santa Cruz do Sul-SC: Edunisc, 2011. p. 26-50.

SÍVERES, Luiz. (Org.). A Extensão universitária como um princípio de aprendizagem. Brasília: Liber Livro, 2013.

PLANO NACIONAL DE EDUCAÇÃO DE 2001 a 2011 e de 2014 a 2024: AS METAS DA EDUCAÇÃO SUPERIOR EM FOCO Talita Zanferari UNOESC $38^{\text {a }}$ Reunião Nacional da ANPEd - 01 a 05 de outubro de 2017 UFMA - São Luís/MA. Publicado em:

http://38reuniao.anped.org.br/sites/default/files/resources/programacao/poste r 38anped 2017 GT11 406.pdf. Acesso em: 20 set. 2020.

PLANO NACIONAL DE EDUCAÇÃO [RECURSO ELETRÔNICO] : CONSTRUÇÃO E PERSPECTIVAS / Ana Valeska Amaral Gomes, Tatiana Feitosa de Britto (organizadoras). - Brasília : Câmara dos Deputados, Edições Câmara : Senado Federal, Edições Técnicas, 2015. 293 p. - (Série obras em parceria ; n. 8) Disponível em: http://pne.mec.gov.brl. Acesso em: 20 set. 2020.

POLÍTICA DE EXTENSÃO DA UNIVERSIDADE ESTADUAL DO TOCANTINS-UNITINS - Aprovada conforme RESOLUÇÃO/CONSEPE/N. 005/2017). Disponível em: www.unitins.br. Acesso em: 26 set. 2020.

RESOLUÇÃO/CONSEPE/N. 005/2017, de 29 de novembro de 2017, aprova a INSTRUÇÃO NORMATIVA/CONSEPE/N. 001/2017- Dispõe sobre os procedimentos operacionais para a institucionalização de ações de extensão na Universidade Estadual do Tocantins - Unitins. Disponível em: www.unitins.br. Acesso em: 26 set. 2020.

INSTRUÇÃO NORMATIVA/UNITINS/N.005/2019/GABREITOR, de 10 de dezembro de 2019, regulamenta as ações de extensão como componente curricular obrigatório nos projetos pedagógicos dos cursos de graduação da Unitins. Disponível em: www.unitins.br. Acesso em: 26 set. 2020.

PDI-Plano de Desenvolvimento Institucional-(PDI-2018-2022). Palmas: Universidade Estadual do Tocantins / UNITINS, 2019. Disponível em: www.unitins.br. Acesso em: 15 set. 2020. 